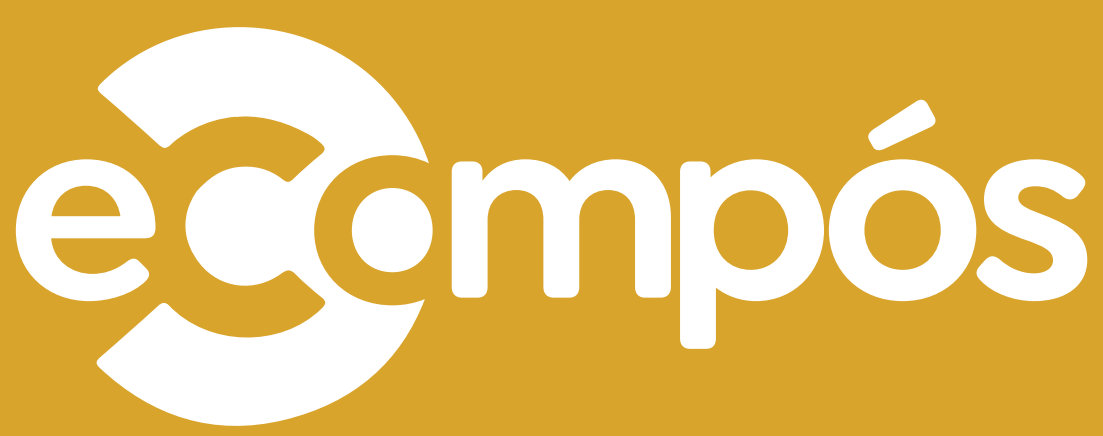

Revista da Associação Nacional dos Programas de Pós-Graduação em Comunicação

ISSN 1808-2599, v. 24, jan-dez, publicação contínua, 2021, p. 1-19.

doi.org/10.30962/ec.2230

\title{
Cosmopoéticas da desobediência informe
} Leitura contra-colonial do regime da extração no catálogo Lumière 


\section{/ resumo}

Considerando o catálogo Lumière como experiência inaugural do cinema mundial, este artigo propõe uma leitura anarquívica de algumas de suas imagens. Diferenciando a operação do cinematógrafo como dispositivo cosmotécnico de arquivamento do mundo e aparelho cosmopoético de invenção de mundos, exploro as formas de inscrição da diferença no arquivo Lumière, por meio de uma arqueologia do sensivel. Confronto o cinema de atrações com um olhar contra-colonial, explicitando tanto o regime da extração que enquadra a diferença quanto as linhas de fuga em que emerge uma potência cosmopoética sobrevivente, nas e entre as imagens, por meio de gestos de desobediência informe.

Palavras-chave: Lumière. Cinema mundial. Arquivo. Violência colonial. Olhar contra-colonial.

\section{Cosmopoéticas de la desobediencia informe: lectura contra-colonial del régimen de extracción en el catálogo Lumière}

Considerando el catálogo Lumière como experiencia inaugural del cine mundial, este artículo propone una lectura anarquívica de algunas de sus imágenes. Diferenciando la operación del cinematógrafo como dispositivo cosmotécnico para archivar el mundo y aparato cosmopoético para inventar mundos, explorams, las formas de inscripción de la diferencia en el archivo Lumière, a través de una arqueología de lo sensible. Confrontamos el cine de atracciones con uma mirada contracolonial, buscando reconocer el régimen de extracción que encuadra la diferencia y las líneas de fuga en las que emerge una potencia cosmopoética superviviente, en y entre las imágenes, a través de huellas de gestos de desobediencia informe.

Palabras clave: Lumière. Cine mundial. Archivo. Violencia colonial. Mirada contra-colonial.

\section{Cosmopoetics of formless disobedience: counter-colonial reading of the regime of extraction in the Lumière catalogue}

Considering the Lumière catalogue as an inaugural experience of world cinema, this article proposes an anarchival reading of some of its images. Distinguishing the operation of the cinematograph as cosmotechnical device for archiving the world and cosmopoetic apparatus for inventing worlds, we explore the forms of inscription of difference in the Lumière archive, through an archaeology of the sensible. We confront the cinema of attractions with a counter-colonial look, making explicit both the regime of extraction that frames difference and the lines of escape in which a surviving cosmopoetic power emerges, in and between images, through traces of gestures of formless disobedience.

Keywords: Lumière. World cinema. Archive. Colonial violence. Counter-colonial look. 


\section{/autor}

\section{Marcelo R. S. RIBEIRO}

Doutor em Arte e Cultura Visual pela

Faculdade de Artes Visuais da Universidade

Federal de Goiás. Professor de História e

Teorias do Cinema e do Audiovisual do

Departamento de Comunicação, Faculdade de Comunicação, da Universidade Federal da Bahia. Coordena o grupo de pesquisa Arqueologia do Sensível.

Universidade Federal da Bahia, Salvador, Bahia, Brasil.

E-mail: marcelorsr@ufba.br

\section{ORCID}

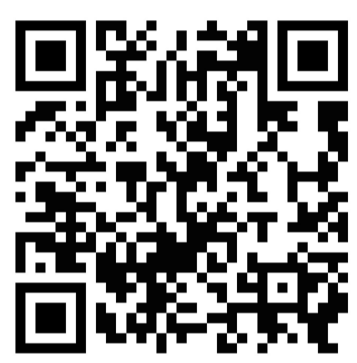




\title{
Introdução: a enciclopédia da mobilidade do mundo
}

Em 2005, a Organização das Nações Unidas para a Educação, a Ciência e a Cultura (Unesco) incluiu os Filmes Lumière no registro do programa Memória do Mundo. Estabelecido em 1992, o programa reconhece diversas formas de "patrimônio documentário" como "correspondentes aos critérios de seleção relativos à significação mundial e ao excepcional valor universal" (UNESCO, 2017, sem paginação, tradução nossa)'. 0 reconhecimento do catálogo Lumière considera um total de 1.405 vistas cinematográficas, pois se perderam 18 do total de 1.423 títulos listados no catálogo comercial da Maison Lumière 2 . Integrando a memória do mundo inscrita em um arquivo universal da humanidade que permanece em construção, aberto e disseminado (RIBEIRO, 2019, p. 29-30), o catálogo Lumière é reconhecido por sua significação mundial e seu valor universal, constituindo uma experiência inaugural de cinema mundial.

De Lumière, será preciso resguardar a luz: "Estava inventado o cinema com Louis Lumière. Louis: luz. Lumière: luz. Informação pura" (FERREIRA, 2016, p. 33). A luz: tudo o que consigna, na imagem, a possibilidade fotográfica do cinema e sua abertura inventiva para a mobilidade do mundo.

\begin{abstract}
O que está em jogo nos rolos [...] gravados pelos cinegrafistas da Lumière com uma espécie de unidade estilística anônima e tácita, é a revelação da mobilidade do mundo, posta em cena com dificuldade, isto é, simplesmente enquadrada [...]. Trata-se de mostrar, nesse batimento de presença e ausência revelado pelo olho estático da câmera, a cadência rítmica do mundo, que exibe com indiferença os gestos do trabalho e os do ócio, e se decompõe no espetáculo infinitamente declinado de aparecimento e desaparecimento dos elementos móveis (MICHAUD, 2014, p. 160-161).
\end{abstract}

Se o cinematógrafo torna tecnicamente possivel que o arquivo universal inclua registros visuais da mobilidade do mundo passíveis de projeção como imagens em movimento, o arquivamento do movimento produzido por esse dispositivo corresponde a um anseio anterior à sua novidade técnica. Assim, o nome Lumière designa, em parte, uma manifestação tardia da herança das Luzes, reinscrevendo no final do século XIX o espírito do Iluminismo do século XVIII, da Encyclopédie de Diderot e D'Alembert e sua reivindicação de universalidade como projeção de um ideal europeu de civilização.

Um dos recursos para a construção desse sistema dos conhecimentos dispersos foi a produção de imagens, e seu horizonte era fundamentalmente humanista e europeu. Em um ensaio sobre as pranchas da Encyclopédie, Barthes (1953, tradução nossa) escreve: "a imagem enciclopédica é humana, não apenas porque o homem é nelas figurado, mas também porque ela constitui uma estrutura de informações" ${ }^{\prime \prime}$ A invenção dos Lumière prolonga e reconfigura o projeto universalista das Luzes e o humanismo europeu. Pretende consagrar a hegemonia francesa no processo de desenvolvimento de técnicas da imagem em movimento e amplia as possibilidades de arquivamento do conhecimento do mundo, indo além da imagem estática e da palavra escrita, capturadas no suporte fixo da página e no precário espaço tradutório entre línguas da Encyclopédie.

1 No original: "corresponding to the selection criteria regarding world significance and outstanding universal value".

2 Os trechos textuais citados e outras informações estão no site do programa Memória do Mundo. Disponível em: <https://en.unesco.org/programme/ mow/register>. Acesso em: 25 jun. 2021.

3 No original: "l'image encyclopédique est humaine, non seulement parce que l'homme y est figuré, mais aussi parce qu'elle constitue une structure d'informations". 
Quando o catálogo Lumière reúne vistas cinematográficas de diversas partes da superfície da terra, tornando possivel uma enciclopédia da mobilidade do mundo, a teia incipiente de suas imagens não alcança, contudo, o sentido sistemático pretendido pela Encyclopédie. Se a abertura do cinematógrafo para o mundo constitui alguma "estrutura de informações", seu objeto não são "os conhecimentos dispersos", mas a própria dispersão do mundo. Informação pura, desde que desdobrados os sentidos do conceito, reescrevendo informação sob rasura e insinuando o conceito de informe $e^{4}$.

o catálogo Lumière insinua a promessa de um arquivamento da mobilidade do mundo como informação sensivel, disponivel para uma enciclopédia por vir, de que o próprio catálogo não constitui mais do que uma sombra. Considerando informação convencionalmente como estruturação de dados $e$ ordenamento formal do existente, o cinematógrafo aparece como dispositivo de registro da circulação das formas, compondo um arquivo visual da mobilidade do mundo: o catálogo Lumière resguarda aqui uma promessa enciclopédica, que deve ser objeto de uma arqueologia dos discursos, saberes e enunciados, bem como de uma arqueologia do visível e da visão. Considerando informação inventivamente como ação do informe, o cinematógrafo aparece como aparelho de registro da dispersão das formas, deslocando o sentido da promessa enciclopédica do catálogo e disseminando os rastros da vaga luminosidade de suas imagens como informação pura e memória informe do mundo, que podem ser compreendidos por uma arqueologia do sensivel ${ }^{5}$.

Pensando o catálogo Lumière como experiência inaugural do cinema mundial, que abre a herança da promessa enciclopédica para uma deriva suplementar, este artigo propõe uma leitura anarquívica de algumas de suas imagens, isto é, uma leitura a contrapelo que busca interrogar a ordem que as organiza no arquivo conformado pelo catálogo. Diferencia-se a operação do cinematógrafo como dispositivo cosmotécnico, na medida em que efetiva a "unificação entre a ordem cósmica e a ordem moral"6 (HUI, 2016, p. 19, tradução nossa) por meio do arquivamento do mundo, e como aparelho cosmopoético, uma vez que perturba a ordem do arquivo e insinua a possibilidade de (re)invenção de mundo(s). Para isso, discutimos a questão da inscrição da diferença no arquivo Lumière, por meio da deriva metodológica de uma arqueologia do sensivel (que suplementa e desloca toda compreensão arqueológica de discursos, saberes e enunciados). Confrontamos o cinema de atrações com um olhar contra-colonial, explicitando o regime da extração que enquadra a diferença, assim como as linhas de fuga em que emerge, nas e entre as imagens, uma potência cosmopoética sobrevivente por meio de gestos de desobediência informe.

\section{0 cinematógrafo como dispositivo cosmotécnico}

O sentido originário da luz difusa associada ao cinematógrafo não implica uma continuidade que atravessaria a história do cinema, nem a existência de um sentido permanente de relação com o princípio ou arkhê que o nome Lumière representa. "Arkhê designa ao mesmo tempo o começo e o comando" (DERRIDA, 2001, p. 11), e como começo e comando, origem e lei da história do cinema, Lumière é uma figura da "toponomologia" e da "função árquica, na verdade patriárquica, sem a qual nenhum arquivo viria à cena nem apareceria como tal" (DERRIDA, 2001, p. 13); é o nome de uma promessa enciclopédica de arquivamento

4 Um maior detalhamento do conceito de informe extrapolaria os limites deste artigo. Em linhas gerais, sua elaboração se desdobra a partir do verbete que Georges Bataille publicou na revista Documents em 1929 (BATAILLE, 2018) e encontra um ponto de condensação em Didi-Huberman (2015).

5 Não é o objetivo nem cabe no escopo deste artigo um detalhamento do debate sobre o conceito de sensível, cuja polissemia se trata, aqui, de buscar disseminar, em vez de conter em uma definição estrita. Irredutíveis ao enunciável e ao visivel, as formas sensiveis e o informe como instância do sensivel correspondem às "formas concretas" que Bataille, em sua posição materialista, contrapunha recorrentemente à "forma ideal", exigindo uma noção de "matéria em que o saber se precipita, e não matéria em que o saber encontraria seu fundamento" (DIDI-HUBERMAN, 2015, p. 297).

6 No original: "unification between the cosmic order and the moral order through technical activities". 
do mundo com imagens em movimento, sob a forma de vistas cinematográficas. A promessa moderna de arquivamento decorre de um mal de arquivo: tanto a uma pulsão de arquivo quanto a uma pulsão de destruição ou pulsão anarquívica, que produz esquecimento e "trabalha para destruir o arquivo" (DERRIDA, 2001, p. 21)7.

Como nome próprio e marca proprietária de um invento tecnológico, Lumière é um dos signos das Luzes, configurando um catálogo decorrente da operação do cinema como dispositivo de arquivamento, na medida em que busca explorar, como todo dispositivo, "a capacidade de capturar, orientar, determinar, interceptar, modelar, controlar e assegurar os gestos, as condutas, as opiniões e os discursos dos seres viventes" (AGAMBEN, 2009, p. 40). Considerando que o conceito de cosmotécnicas designa as diferentes formas possíveis de "unificação entre a ordem cósmica e a ordem moral por meio de atividades técnicas"8 (HUI, 2016, p. 19-20, tradução nossa), pode-se dizer que, ao arquivar o mundo, o cinematógrafo opera como dispositivo cosmotécnico, na medida em que a tecnologia cinematográfica efetiva o enquadramento do mundo como reserva disponível para extração?.

Conceber o cinema como dispositivo cosmotécnico passa por reconhecer (1) o pertencimento do aparelho cinematográfico à categoria geral da técnica, (2) a possibilidade geral de seu uso produtivo ou poético em sentido estrito (tékhnē como poiesis) e (3) a tendência moderna de configuração do cinema como forma de enquadramento e redução do mundo a uma reserva disponível para extração, uma vez que pode ser medida, calculada e explorada. Posto que participa do projeto moderno, que, como argumenta Hui (2016), separa técnica e cosmologia, o cinema contribui para a negação moderna do caráter cosmotécnico de toda técnica, isto é, de seu fundamento cósmico. Na cosmotécnica moderna, que denega a si mesma e procura se afirmar apenas como técnica, "o cosmos é visto como uma reserva permanente explorável, de acordo com o que Heidegger denomina imagem de mundo (Weltbild)"10 (HUI, 2016, p. 21, tradução nossa).

Compreender o cinematógrafo como dispositivo cosmotécnico implica reconhecer os fluxos globais, cuja economia delimita o alcance geográfico de suas vistas, e compreender o primeiro cinema como cinema global (GUNNING, 2015). A promessa enciclopédica do cinematógrafo corresponde às possibilidades e limites de sua operação como dispositivo, que arquiva traços do mundo em um catálogo de vistas cinematográficas construído no decorrer de uma circulação global movida por interesses comerciais.

No final de 1895, apenas alguns meses após os irmãos Lumière revelarem uma máquina que podia gravar, processar e projetar imagens em movimento, a Maison Lumière um nome comum para a empresa cinematográfica global que evoca domesticidade e trabalho manual, omitindo quaisquer laços com a fábrica industrial - começou a treinar uma equipe de cinegrafistas nas operações idiossincráticas do cinématographe.

\footnotetext{
7 É importante enfatizar que, nessa concepção, o arquivo não apenas está sujeito ao risco de esquecimento, como um acidente posterior ao arquivamento. Além disso, é preciso reconhecer que todo arquivo produz esquecimento, seleciona o que se deve preservar e determina o que se pode ou se deve destruir. Nesse sentido, não há arquivo sem o esquecimento decorrente de uma violência anarquívica, que opera como uma força de fundação do arquivo.

8 No original: "unification between the cosmic order and the moral order through technical activities".

9 Ao pensar o cinema como dispositivo cosmotécnico, consideramos como pano de fundo a distinção conceitual proposta por Yuk Hui (2016, p. 4, n. 3) entre (1) a técnica [technics] como categoria geral das artes do fazer, (2) a tékhnē como concepção grega dessas artes do fazer, que, em uma conferência de 1953, Heidegger (2007) entendeu como poiesis e como produzir [Hervorbringen], e (3) tecnologia [technology] como designação do desenvolvimento em direção à automação que caracteriza modernidade europeia, que faz da técnica uma forma de armação ou enquadramento [Ge-stell] do mundo, reduzido à condição de reserva em posição de subsistência [Bestand], disponível para exploração, transformação, armazenamento e distribuição (HEIDEGGER, 2007, p. 382). o debate filosófico mais amplo em que se inserem Heidegger e Hui ultrapassa os limites deste artigo e inclui tanto figuras do debate ocidental contemporâneo, como Gilbert Simondon e Bernard Stiegler, quanto uma série de outros filósofos do Leste [East], termo que, para Hui (2016, p. 3, n. 2), designa a Ásia Oriental (China, Japão, Coréia etc.), área em que ele identifica a influência do confucionismo, do budismo e do taoísmo.
}

10 No original: "the cosmos is seen as na exploitable standing-reserve, according to what Heidegger calls the world picture (Weltbild)". 
No ano seguinte, os operadores assumiram o controle, demonstrando as características da câmera cinematográfica Lumière em Londres, Roma, Nova York, Frankfurt, Madrid, Moscou, Budapeste, Cidade do México, Sidney, Argel e Saigon. Em cada novo lugar, os operadores exibiram a máquina e projetaram diversas vues. Eles também gravaram in loco e, ao fazer isso, expandiram o escopo geográfico da coleção Lumière. Quando a operação se encerrou em 1905, o arquivo Lumière continha 1.428 filmes. Mais de oitocentos tinham sido reunidos em expedições de produção de imagens ao redor do mundo ${ }^{11}$ (GROO, 2019, p. 46-47, tradução nossa).

Na medida em que o cinematógrafo opera como dispositivo cosmotécnico, Lumière é o nome de uma empresa de arquivamento do mundo como globo, isto é, como espaço de circulação comercial de cinegrafistas e imagens. O catálogo encontra seu fundamento em um princípio econômico de retorno circular à origem e manifesta sua produtividade mimética e simbólica como "catálogo interminável da circulação dos elementos móveis" (MICHAUD, 2014, p. 12). A circulação econômica delimita um centro para a mobilidade do olho variável do cinematógrafo, que é subordinada ao comércio, e recaptura a abertura inventiva de sua relação com o mundo, por meio da formalização e da repetição de padrões:

Os temas mais populares da coleção Lumière - chegadas, partidas, cenas de rua, panoramas e procissões - também viajavam. A repetição de categorias visuais e composições através de partes radicalmente diferentes do mundo equilibrava a infinita diferença da exploração global com uma estrutura do mesmo. As expedições de operadores garantiam a simultaneidade global da chegada do cinema [...] $]^{12}$ (GROO, 2019, p. 64).

Em sua operação como dispositivo cosmotécnico, a economia do catálogo Lumière é tanto comercial e financeira, associada à circulação global de cinegrafistas e ao retorno das vistas à domesticidade metropolitana, quanto simbólica e estética, relacionada à circulação visual de elementos móveis, reunidos no catálogo sob signos de similaridade, conforme uma unidade estilística que define uma estrutura do mesmo. Entre o comercial e o simbólico, a economia do catálogo determina as possibilidades e os limites da ambição ou a promessa enciclopédica do cinematógrafo, compondo um arquivo visual.

\section{0 cinematógrafo como aparellho cosmopoético}

Quando interroga a concepção moderna da tecnologia como uma totalidade unificada e homogênea, separada e contraposta à natureza, Hui (2019, p. 39-40, tradução nossa) propõe o que denomina “um pensamento cosmotécnico, que situa a tecnologia em sua gênese e a vincula ao seu fundamento [terra, solo: ground], que é a realidade cósmica", tornando possível "uma abertura de um verdadeiro pluralismo, ou uma cosmotécnica múltipla"13.

11 No original: "By the end of 1895, mere months after the Lumière brothers had revealed a machine that could record, process, and project moving images, the Maison Lumiere-a common name for the global film enterprise that evokes domesticity and handicraft, eliding any ties with the industrial factory-began training a team of filmmakers in the idiosyncratic operations of the cinématographe. The following year, the operators took over, demonstrating the features of the Lumière film camera in London, Rome, New York, Frankfurt, Madrid, Moscow, Budapest, Mexico City, Sydney, Algiers, and Saigon. At each new location, the operators exhibited the machine and projected several vues. They also recorded on-site and, in so doing, expanded the geographic scope of the Lumière collection. When the operation ended in 1905, the Lumière archive contained 1,428 films. More than eight hundred had been gathered on image-making expeditions around the world.".

12 No original: "The most popular themes in the Lumière collection-arrivals, departures, street scenes, panoramas, and processions - also traveled. The repetition of visual categories and compositions across radically different parts of the world balanced the infinite difference of global exploration with a structure of the same. The operator expeditions guaranteed the global simultaneity of cinema's arrival [...]".

13 No original: "a cosmotechnical thinking, which situates technology in its genesis and attaches it to its ground, which is the cosmic reality" (p. 39); "an opening of a true pluralism, or a multiple cosmotechnics" (p. 40). 
Ainda sobre o tema, o autor ressalta:

Quando a tecnologia em si se torna o fundamento [ground], então a realidade cósmica é obscurecida, e a aceleração tecnológica se torna o valor de todos os valores. É por isso que tentei mostrar que não devemos conceber a tecnologia moderna como a totalidade ou o fundamento [ground], mas que em vez disso é necessário e urgente conceber diferentes cosmotécnicas em que a tecnologia é reconectada com o cosmos e a moral. Isso exigirá repensar a transformação da episteme, que por sua vez condiciona uma experiência política, social e estética diferente ${ }^{14}$ (HUI, 2019, p. 226, tradução nossa).

Se "é necessário considerar diferentes cosmotécnicas para conceber a possibilidade de bifurcações de futuro e história mundial"15 (HUI, 2019, p. 265, tradução nossa), argumentamos que, em termos conceituais, só é possível confrontar uma forma de "unificação da ordem cósmica e da ordem moral" que obscurece a realidade cósmica, e só se torna possivel conceber e desenvolver diferentes cosmotécnicas e insinuar diferentes futuros por meio da introdução de uma pulsão de desordem que perturba o fechamento cosmotécnico (no qual a cosmotécnica específica associada à modernidade colonial pode aparecer apenas como técnica).

Há cosmopoéticas sempre que essa pulsão de desordem desunifica e desacopla ordem cósmica e ordem moral, deslocando toda forma de unificação e criando outras relações entre humanidade, tecnologia e natureza, entre moral e cosmos, entre mundo comum e comunidade política, entre mundanidade, humanidade e comum. A transformação da episteme opera uma reconfiguração cosmotécnica, "uma cosmopoiesis em que a coexistência é favorecida, em vez da dominação da humanidade e da tecnologia sobre a natureza"16 (HUI, 2019, p. 226, tradução nossa). Toda cosmopoética encadeia uma perturbação e uma reconfiguração cosmotécnica ${ }^{17}$.

Para situar a tecnologia do cinematógrafo Lumière e vinculá-lo à sua terra, solo ou fundamento cósmico, é preciso pensar a operação cosmotécnica singular que o define. Isso exige uma leitura a contrapelo do catálogo Lumière e de suas vistas cinematográficas, na medida em que condensam economicamente (no duplo sentido que este artigo desdobra: comercial/financeiro e simbólico/estético) o projeto cosmopolítico colonial-moderno do humanismo europeu. É preciso descolonizar o estudo do catálogo Lumière e desativar a captura proprietária, humanista e colonial-moderna de suas imagens, confrontando criticamente a "despolitização do olhar" (SANOGO, 2011) por meio da reivindicação de um olhar contra-colonial que torne possivel reconhecer o cinema como aparelho cosmopoético.

14 No original: "When technology itself becomes the ground, then the cosmic reality is obscured, and the technological acceleration becomes the value of all values. This is why I have attempted to show that we must not conceive modern technology as the totality or the ground, but rather that it is necessary and urgent to conceive different cosmotechnics in which technology is reconnected with the cosmos and the moral. This will demand a rethinking of the transformation of the episteme, which in turns conditions a different political, social, and aesthetic experience".

15 No original: "it is necessary to consider different cosmotechnics in order to conceive the possibility of the bifurcations of future and world history".

16 No original: "a cosmopoiesis in which coexistence is favored instead of the domination of humankind and technology over nature".

17 Hui não aprofunda a referência à cosmopoiesis, nem converte a grafia grega da palavra em um conceito como o de cosmopoéticas. Entendemos que sua argumentação em favor de "uma reabertura do conceito de técnica como múltiplas cosmotécnicas e do futuro das imaginações tecnológicas" (HUI, 2019, p. 277, tradução nossa) [No original: "a reopening of the concept of technics as multiple cosmotechnics and the future of technological imaginations."] pode ser articulada, em sua amplitude de sentidos possíveis, por meio do conceito de cosmopoéticas. Isso implicará desdobrar o conceito de cosmopolíticas (RIBEIRO, 2019) em seu sentido humanista, associado à herança do cosmopolitismo e ao multiculturalismo, e em seu sentido terrano, associado ao debate sobre os limites do humanismo e do antropocentrismo, aprofundado hoje, de modo crucial, com o reconhecimento do Antropoceno. 


\section{O doméstico e o excursivo}

Há diversas possibilidades de classificação das vistas do catálogo Lumière ${ }^{18}$. Se a circulação dos cinegrafistas Lumière ao redor do mundo participa do "impulso colonial de capturar e catalogar uma totalidade global"19 (GROO, 2019, p. 49, tradução nossa), uma das linhas de força - e de fuga - que se abre anarquivicamente no catálogo Lumière está relacionada às formas de inscrição da diferença. No decorrer do movimento duplo que estabelece, a circulação global de cinegrafistas produz uma diferenciação instável entre vistas de experiências domésticas, situadas em espaços metropolitanos, e vistas de experiências excursivas, que estabelecidas em espaços coloniais. Para Groo (2019, p. 54, tradução nossa), o doméstico e o excursivo "deslocam categorias mais familiares e muito mais gerais como 'actualités' ou 'filmes de viagem"'20, amplamente utilizadas para classificar as vistas Lumière e identificar gêneros característicos do primeiro cinema e seus modos de misturar ficção e não ficção ao registrar realidades próximas e distantes, familiares ou exóticas (COSTA, 2005, p. 192-210).

O doméstico inclui registros da vida familiar, como Repas de bébé (no. 88, 1895), em que vemos Auguste Lumière, sua esposa Marguerite e sua filha Andrée, e Repas en famille ( $n$ o. 89, 1896), em que vemos a irmã de Auguste e Louis, Jeanne Koehler, esposa de René Koehler, com os filhos do casal, Madeleine e Marcel. Há também registros de atividades de trabalho, como Démolition d'un mur (no. 40, 1896), em que Louis filma seu irmão, Auguste, enquanto ele supervisiona a demolição de uma parede na fábrica Lumière, em Lyon, e Laveuses sur la rivière (no. 626, 1897), em que o trabalho de mulheres aparece em primeiro plano, na camada inferior da imagem, enquanto homens observam o rio e, atrás deles, na camada superior da imagem, transcorrem os movimentos do cotidiano da cidade. Nas vistas de experiências domésticas, traços da vida em comum se acumulam no arquivo catalogado sob a luz de Lumière, compondo o mosaico de paisagens culturais euro-ocidentais que corresponde à sua topo-nomologia.

As experiências excursivas emergem em registros da diferença, frequentemente capturada sob o signo do exótico por cinegrafistas viajantes, como em Danse mexicaine (no. 353, 1896), parte da série de vistas decorrentes da viagem de Gabriel Veyre ao México e a outros países da América Latina (1896-1897), ou Les Aïnos à Yeso, I (no. 741, 1897) e II (no. 742, 1897), parte da série de vistas decorrentes da viagem de Constant Girel ao Japão (1896-1897). Ao exotismo evidente da inscrição espetacular da diferença em danças rituais acrescentam-se formas de registro da diversidade e das diferenças menores associadas ao cotidiano, como Repas en famille (no. 734, 1897), em que Girel filma uma família japonesa ao tomar chá, e Repas d'Indiens (no. 351,1896 ), em que Veyre captura um conjunto de pessoas a que o título da vista (quando de sua exibição na Cidade do México) se referia como "Um grupo de índios ao pé da árvore da Noite Triste em Popotla" ${ }^{21}$. Nas vistas de experiências excursivas, insinua-se uma consciência global da diversidade humana, vista a partir da posição pretensamente universal do sujeito europeu, compondo um mosaico de figuras da diferença, capturadas sob o signo da similaridade.

18 No site Catalogue Lumière (https://catalogue-lumiere.com/)), é possível acessar informações detalhadas sobre cada uma das vistas, que são classificadas de acordo dois critérios básicos: os lugares em que foram filmadas (países e cidades) e os operadores que foram responsáveis pelas filmagens. As informações do site foram retiradas da coletânea La production cinématographique des Frères Lumière (1996), dirigida por Aubert e Seguin, e do CD-ROM que acompanhava o volume. Além desses critérios classificatórios básicos, o site identifica as vistas por meio de diversos metadados. A lista completa das vistas pode ser acessada e reutilizada a partir do seguinte repositório do GitHub: https:/github.com/greyscalepress/ catalogue-lumiere.

19 No original: "the colonial impulse to capture and catalog a global totality".

20 No original: "displace more familiar and far more general categories like 'actualités' or 'travel films"'.

21 No original: “Un grupo de indios al pie del árbol de la Noche Triste en Popotla”. (Disponível em: <https://catalogue-lumiere.com/repas-dindiens/>. Acesso em: 02 jun. 2020): 


\section{Contraponto: Repas de bébé e Repas d'Indiens}

Delimitando uma economia comercial e simbólica, a operação global dos cinegrafistas suplementa os registros de paisagens próximas à domiciliação (patri)árquica do catálogo Lumière com registros de outras paisagens, cujo distanciamento geográfico em relação à Europa é recorrentemente reinscrito sob o signo da similaridade. O movimento dos operadores compõe derivas ao redor do mundo, mas volta a se inscrever no círculo econômico que reenvia à domesticidade da Maison Lumière, como espaço toponomológico de arquivamento e consignação. A operação do catálogo Lumière como dispositivo cosmotécnico trabalha para exibir a diferença, arquivando seus traços sob a forma de diversidade cultural e, ao mesmo tempo, buscando apagar o processo de produção desse gesto de arquivamento. Ler anarquivicamente é interrogar o apagamento do processo de produção do arquivo. Ler o catálogo Lumière anarquivicamente é, em suma, buscar os rastros do que sua promessa enciclopédica denega, e parte desses rastros se condensa em torno das formas de inscrição da diferença, seguindo indícios frequentemente considerados acidentais ou irrelevantes.

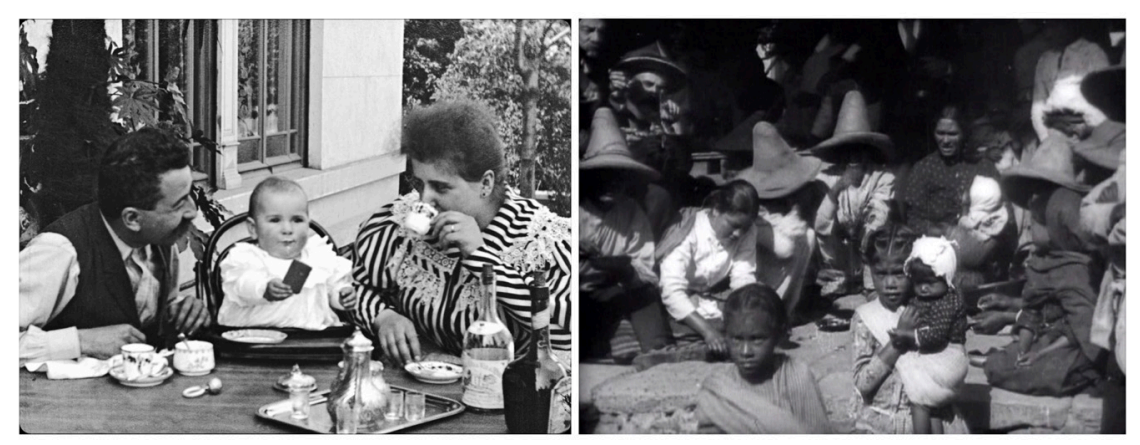

Figura 01: Contraponto colonial-moderno: (a) Repas de bébé e (b) Repas d'Indiens.

Fonte: Capturas de tela de arquivos digitais ${ }^{22}$.

O contraponto entre Repas de bébé (no. 88, 1895) ${ }^{23}$ e Repas d'Indiens (no.. 351, 1896) 24 permite explorar algumas das frestas que a leitura anarquívica pode abrir no catálogo Lumière, revelando, em seu interior, indícios da violência colonial que o funda. "Repas d'Indiens faz referência explicitamente a uma tradição de filmes de 'refeição familiar' que começou em 22 de março de 1895, quando Luis Lumière filmou Repas de bébé"25 (GROO, 2019, p. 71).

22 Repas de bébé (35 seg., 1895). In: LUMIÈRE ! Le Cinématographe 1895-1905 - Les films Lumière présentés par Bertrand Tavernier et Thierry Frémaux. Direção/Realização: Maison Lumière. Produtora: Maison Lumière. Distribuidora: Instituto Lumière; France TV. França, 2015. Blu-ray, 2 discos (90 min.; coletânea de vistas de duração variável com até 1 min. cada uma), estéreo (para os comentários contemporâneos), preto e branco. Digitalização 1080p de filme 35mm. Razão de aspecto: 1,33:1. Idioma: francês; legendas: francês.

Repas d'Indiens (46 seg., 1896). In: LES FILMS LUMIĖRE. Direção/Realização: Maison Lumière. Produtora: Maison Lumière. Distribuidora: Gedeon. Japão, 2005. DVD, disco 1 de caixa de 4 discos (respectivamente: 95 min.; 98 min.; 95 min.; 103 min.; coletâneas de vistas de duração variável com até 1 min. cada uma), estéreo (para os comentários contemporâneos de Bertrand Tavernier), preto e branco. Digitalização 480p de filme 35 mm. Razão de aspecto: 1,33:1. Idioma: francês; legendas: japonês.

23 Disponivel em: <https://www.youtube.com/watch?v=CvrDVlj7tCk>; <https://www.youtube.com/watch?v=2b2AoDYlv-g>. Acesso em: 02 jun.2020.

24 Disponivel em: <https://www.youtube.com/watch?v=Tt1uP91eOI8>; <https://www.youtube.com/watch?v=sJHxQ_AWmoM>. Acesso em: 02 jun.2020.

25 No original: "Repas d'Indiens explicitly references a tradition of "family meal" films that began on March 22, 1895, when Louis Lumière filmed Repas de bébé". 
A cena familiar inaugural do cinematógrafo é frequentemente citada como um exemplo do regime de mostração (GAUDREAULT, 2008), na medida em que está entre os usos iniciais da máquina cinematográfica, destinados à exibição da própria capacidade técnica do aparelho de registrar e reproduzir imagens em movimento. Ao mesmo tempo, desde sua exibição como parte do programa da primeira sessão pública paga do cinematógrafo Lumière, no Grand Café, em 28 de dezembro de $1895^{26}$, a vista que se tornaria a entrada 88 do catálogo constitui também um exemplo inaugural do cinema de atrações (GUNNING, 2015).

Quando se estabelece o contraponto entre as vistas 88 e 351, as categorias mostração e atração se revelam insuficientes para compreender criticamente o catálogo Lumière. A vista 351 "repete um dos filmes mais icônicos da coleção Lumière, não apenas subvertendo uma forma de ver e filmar, mas abordando e criticando diretamente uma das mitologias fundacionais do arquivo Lumière"27 (GROO, 2019, p. 69, tradução nossa). Ali onde Repas de bébé parecia ser redutivel aos conceitos de regime de mostração e atração, Repas d'Indiens introduz o espaçamento da diferença, e a compreensão de suas imagens exige a introdução de conceitos, como os de contenção, confinamento, exposição e extração, que permitem pensar a operação do cinema como dispositivo cosmotécnico e reconhecer a potência cosmopoética que abriga.

O sentido cosmotécnico da vista 351 está relacionado à tentativa de registrar a diferença dos Indiens diante de um olhar branco que se pretende universal e técnico. 0 interesse da vista reside, justamente, no fato de que a imagem registra a violência da relação entre sujeitos brancos e indígenas como uma violência de disposição dos corpos indígenas - como se fossem uma reserva permanente, disponível para exploração e extração. Seu sentido cosmotécnico é fundamentalmente colonial, baseado em um horizonte de captura, neutralização e arquivamento da diferença (os corpos dos outros como índice opaco de diferença radical) como diversidade (os Indiens como símbolo domesticado do exótico).

Nas suas tentativas de fazer com que os índios olhem para a câmera, os brancos procuram dirigilos, por meio da contenção de seus corpos, posturas e olhares, e essa contenção busca assegurar, com a violência variável de seus gestos, o confinamento e a exposição da diferença: é preciso um dispositivo sobre os corpos diante do aparelho para extrair da diferença um espetáculo exótico. A captura cosmotécnica da diferença como diversidade cultural procura domesticar as figuras de alteridade, mas o que torna a entrada 351 singular é o modo como revela as tensões constitutivas do processo, o embate entre sujeitos europeus, mexicanos e indígenas. "Mais do que qualquer outro filme Lumière, Repas d'Indiens gira em torno da representação de autoridade e resistência"28 (GROO, 2019, p. 70, tradução nossa).

\section{Curto-circuito: a série Ashanti}

É no curto-circuito entre o doméstico e o excursivo que se condensa o nexo irredutível entre modernidade e colonialidade, tal como se inscreve no catálogo Lumière. A diferenciação entre o doméstico e o excursivo opera de modo transversal no catálogo, mas a instabilidade dessa diferença se revela, de forma paradigmática, no curto-circuito que atravessa uma série como "A aldeia Ashanti em Lyon" [Le village achantis à Lyon], que registra a diferença, tal como foi exibida em uma exposição colonial em Lyon, no ano de 1897.

26 o programa completo e algumas informações adicionais podem ser conferidos em: http://www.celebration-lumiere.org/historique/la-premiereseance.html.

27 No original: "repeats one of the most iconic films in the Lumière collection, not only overturning a way of seeing and filming but directly addressing and critiquing one of the foundational mythologies of the Lumiere archive".

28 No original: “More than any other Lumière film, Repas d'Indiens hinges upon the representation of authority and resistance". 
“Em 18 de abril de 1897, um artigo no Lyon républicain anunciava a chegada de um novo espetáculo no Parc de la Tête d'or. Um antigo engenheiro naval, Ferdinand Gravier, tinha trazido um grupo de africanos da Costa do Ouro para a cidade francesa"29 (GROO, 2019, p. 55, tradução nossa). 0 grupo era formado por 200 pessoas vindas da colônia britânica na África ocidental. Enquanto ocorria essa viagem dos Ashanti a Lyon, estava em andamento a guerra colonial associada à conquista militar britânica de territórios disputados com a França e outras potências europeias, em meio à partilha imperialista da África Ocidental, diante do que Uzoigwe (2010, p. 41) descreve como "a resistência decidida e frequentemente difícil de vencer dos africanos".

É nesse contexto que se deve situar o que vemos na série Ashanti do catálogo Lumière. Os sujeitos das experiências excursivas são geralmente alguns dos cinegrafistas Lumière. Registrada por cinegrafista(s) atualmente desconhecido(s), a série Ashanti é um exemplo de experiência excursiva que se inscreve na domesticidade metropolitana: são os Ashanti que realizam fisicamente a excursão, e é seu ponto de vista que permanece, ao mesmo tempo, excluído e visado pelas imagens. Sanogo (2011) data a exposição entre 17 de abril e 20 de julho de 1897. Groo (2019, p. 56, tradução nossa) contabiliza 14 vistas da exposição ${ }^{30}$, discutindo como o catálogo as arquiva:

Entre o dia da abertura e 17 de maio, uma equipe rotativa de operadores Lumière fez catorze filmes da exposição, incluindo Danse du sabre I e Danse du sabre II. Além de exibições de corpos dançantes, a coleção Ashanti inclui desfiles, refeições familiares e crianças que brincam. Ainda assim, as descrições que acompanharam esses filmes no catálogo Lumière original recusam-se a detalhar seus conteúdos visuais ou a distinguir entre eles ${ }^{31}$.

As descrições textuais de todas as vistas da série repetem as mesmas informações gerais: "Estas vistas foram capturadas em uma aldeia de Aschantis [sic] que foi instalada em Lyon, no momento da Exposição. Todas essas vistas são muito interessantes; seus títulos são suficientemente explicativos" ${ }^{\prime 32}$. Para Groo (2019, p. 56, tradução nossa), os textos associados à série "operam em conjunção para conferir à coleção Ashanti uma imobilidade administrável" ${ }^{\prime 3}$. Nesse sentido, o arquivamento da diferença, capturada e exposta na domesticidade metropolitana, inscreve seus traços sob o signo da similaridade, por meio de descrições textuais repetidas, títulos genéricos e recorrências visuais. Isso permite administrar a emergência da diferença Ashanti no catálogo Lumière, por meio de estratégias de fixação e contenção da mobilidade dos corpos negros e da inquietude da diferença.

As estratégias cinematográficas de fixação se destinam à reprodução de um enquadramento frontal centrípeto dos sujeitos representados, extraindo da diferença os sentidos do exótico. Esse exotismo visual suplementa o dispositivo físico de confinamento do zoológico humano, cujo fundamento é a contenção dos corpos negros no espaço da exposição. Se esse tipo de espetáculo constitui um dispositivo de exposição

29 No original: “On April 18, 1897, an article in the Lyon républicain announced the arrival of a new spectacle in the Parc de la Tête d'or. A former naval engineer, Ferdinand Gravier, had delivered a group of Africans from the Gold Coast to the French city."

30 A série "A aldeia Ashanti em Lyon" é composta por 14 vistas: as entradas 441 (Danse du sabre I), 442 (Danse du sabre II), 443 (Danse de jeunes files), 444 (Danse de femmes), 445 (Danse du féticheur), 446 (Déflé de la tribu), 447 (Repas de négrillons I), 448 (Repas de négrillons II), 449 (Toilette d'un négrillon I), 450 (Toilette d'un négrillon II), 451 (Récréation des négrillons), 452 (Écoles des négrillons), 564 (Nègres Achantis : danse d'hommes) e 565 (Nègres Achantis : leçon de danse). Disponivel em: <https://catalogue-lumiere.com/series/info-five-51/>. Acesso em: 02 jun. 2020.

31 No original: "Between opening day and May 17, a rotating cast of Lumière operators made fourteen films of the exposition, including Danse du sabre I and Danse du sabre II. In addition to displays of dancing bodies, the Ashanti collection includes parades, family meals, and children at play. And yet, the descriptions that accompanied these films in the original Lumiere catalog refuse to elaborate on their visual contents or distinguish between them".

32 No original: “Ces vues ont été prises dans un village d'Aschantis qui était installé à Lyon, au moment de l'Exposition. Toutes ces vues sont très intéressantes; leurs titres sont suffisamment explicatifs". Disponivel em: <https://catalogue-lumiere.com/series/info-five-51/>. Acesso em: 02 jun. 2020.

33 No original: "The titles and descriptions work in conjunction to imbue the Ashanti collection with a manageable stillness." 
da diferença que se difundiu no decorrer do século XIX, contribuindo para a difusão popular do racismo pseudocientífico, a série Ashanti converte o cinema em uma continuação do zoológico humano por outros meios: “Do espetáculo vivo (a exposição), passamos à imagem viva (o cinema), do Outro importado (o exibido), chegamos ao Outro duplicado (a imagem fixa): mais do que a uma mudança de escala, é à emergência de uma outra dimensão da alteridade que assistimos"34 (BANCEL et al., 2002, p. 17, tradução nossa).

\section{O regime da extração: Danse du Sabre, II}

O regime de inscrição da diferença como alteridade colonial e diversidade cultural permanecerá incompreensivel se continuarmos a compreender o catálogo Lumière por meio categorias como mostração, atração e narração, sem reconhecer o transbordamento da modernidade pela colonialidade que a atravessa e a constitui. A série Ashanti faz parte do conjunto das vistas registradas nas exposições coloniais, que configura um dos gêneros das representações da África no catálogo Lumière (SANOGO, 2011): ao lado dos filmes de viagem ou travelogues, emergem os traços do "gênero homanimal" [manimal genre].

Propondo uma interrogação ética e política das atrações, Sanogo (2011, tradução nossa) afirma em palestra que, apesar de aspirar ao reconhecimento da historicidade do cinema dos primeiros tempos, os trabalhos de Gunning e Gaudreault sobre o cinema de atrações não incluem uma discussão mais aprofundada das relações das atrações com a participação dos Lumière na mise-en-scène do projeto colonial. "O gênero homanimal, por exemplo, deve ser incluído no ou ao menos articulado com o cinema de atrações para oferecer um relato mais complexo desses dias iniciais do cinema"35, considera Sanogo (2011, tradução nossa), que propõe duas perguntas relacionadas: "O que podemos dizer do regime de espectatorialidade do zoológico humano?" ${ }^{36}$ e "Qual é a natureza do espectador colonial?" ${ }^{\text {"37. }}$

Não é possivel compreender o regime de espectatorialidade do catálogo Lumière e do cinema de atrações sem relacioná-lo com o trabalho de confinamento e exposição da diferença no zoológico humano e com a demanda por contenção que define o olhar do espectador colonial, configurando o que propomos denominar regime da extração (em contraposição e como suplemento ao conceito de regime da atração). 0 reconhecimento do nexo entre o regime espectatorial do cinema de atrações, associado a um interesse na experiência do choque, e o regime espectatorial do zoológico humano, que depende da constituição de um espectador colonial diante de formas de diferença contidas e expostas, é o que pode tornar legivel, nos traços visíveis das vistas Lumière, os rastros do apagamento fundacional da violência colonial. Esse apagamento é o que torna possivel a operação cosmotécnica, extraindo, da diferença, à medida em que é confinada e exposta, uma mais-valia de espetáculo exótico.

Nesse sentido, o conceito de cinema de atrações corrobora o apagamento fundacional da violência colonial (a violência do processo de extração de mais-valia espetacular, assim como de energia de trabalho escravo, recursos naturais como matéria-prima etc.), que corresponde à operação do cinematógrafo Lumière como dispositivo cosmotécnico, unificando a ordem moral do humanismo europeu e a ordem cósmica, e obscurecendo a dimensão extrativista de sua relação colonial com a diferença e com o mundo.

\footnotetext{
34 No original: “On April 18, 1897, an article in the Lyon républicain announced the arrival of a new spectacle in the Parc de la Tête d'or. A former naval engineer, Ferdinand Gravier, had delivered a group of Africans from the Gold Coast to the French city."

35 No original: "The manimal genre for example must be included or at least articulated with cinema of attractions to give a more complex account of this early days of cinema".
}

36 No original: "What do we make of the spectatorship regime of the human zoo?".

37 No original: "What is the nature of the colonial spectator?". 


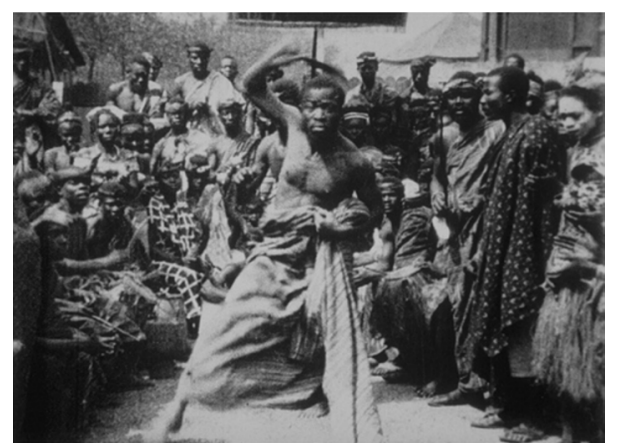

Figura 02: Virada contra-colonial, levante fracassado, desobediência informe.

Fonte: Página dedicada à vista 441, Danse du sabre, I, no site Catalogue Lumière ${ }^{38}$.

Uma das vistas da série Ashanti que consideramos paradigmática pelo modo como torna legivel a operação do cinematógrafo como dispositivo cosmotécnico, e por tornar possível abrir anarquivicamente uma fresta em que se insinua uma potência cosmopoética, é Danse du Sabre, I (no. 441, 1897) ${ }^{39}$. Quando a descrição genérica da série Ashanti é complementada por uma tentativa de detalhar o conteúdo da vista 441, interpretando os movimentos que ela registra, por meio do verbo imitar [mimer], atribui-se um som imaginário à mudez irreparável de suas imagens: "Dois homens armados com uma faca imitam um combate singular, ao som do tambor e das palmas"40. 0 enquadramento é centrípeto: homens e mulheres, bebês, crianças e, em sua maioria, adultos Ashanti, alguns sentados, outros em pé, delimitam, no espaço representado pela imagem, um semicírculo em torno dos dois homens que dançam. Algumas dessas pessoas dançam, outras batem palmas, um homem toca um tambor, outros parecem conversar entre si, enquanto assistem à dança duplamente centralizada, em torno da qual se constitui, no fora de campo frontal, um semicírculo invisivel, em que se situam os sujeitos detentores do olhar.

No centro do círculo, com o enquadramento centrípeto, a operação de extração da mais-valia espetacular da diferença procura converter os corpos dos dois homens em fetiches exóticos, como atrações principais da vista 441. Compreender a Danse du Sabre, I como exemplo do cinema de atrações é reiterar inadvertidamente a violência extrativista da operação do cinematógrafo como dispositivo cosmotécnico, participando do apagamento da violência colonial que torna possivel representar a diferença como um conjunto exótico de atrações. 0 arquivo e sua ordem se constituem por meio desse apagamento, mas o aparelho registra também um transbordamento: na vista 441, uma pulsão anarquívica emerge das relações centrífugas entre os corpos e o enquadramento, perturbando sua operação como dispositivo cosmotécnico e abrigando em suas imagens uma frágil potência cosmopoética, que se condensa nos recorrentes movimentos de virada de um dos homens em direção ao aparelho.

38 Disponivel em: <https://catalogue-lumiere.com/danse-du-sabre-i/>. Acesso em 02 jun. 2020.

39 Disponivel em: <https://www.youtube.com/watch?v=uNVtkCQwL9E>. Acesso em: 25 jun.2021.

40 Tradução nossa. No original:: "Deux hommes armés d'un couteau miment un combat singulier, au son du tam-tam et des battements de mains" Disponivel em: <https://catalogue-lumiere.com/danse-du-sabre-i/>. Acesso em: 02 jun. 2020. 


\section{Considerações finais: a desobediência informe como fresta cosmopoética}

Com o intuito de diferenciar forças constitutivas do cinema, de modo geral, e com base na abordagem parcial do catálogo Lumière, em particular, entendido como experiência inaugural e paradigmática, diferenciamos a operação do cinema como dispositivo cosmotécnico e aparelho cosmopoético.

A relação entre cosmotécnica e cosmopoética pode ser correlacionada à diferença entre dispositivo e aparelho: "O aparelho deve respeitar a lei de acolhimento do evento" (DÉOTTE, 2004, p. 99), mas "não há garantias de que um dispositivo (dispositio: disposição, arranjo, regulamento, administração, cláusula de um testamento) tenha muitas preocupações com o estrangeiro: dispositivo de segurança, dispositivo militarpolicial etc." (DÉOTTE, 2004, p. 102). Para pensar essa diferenciação, destacamos a vista 441, Danse du Sabre, I.

É preciso pensar a diferença entre aparelho e dispositivo no interior das imagens, entendidas como campos de forças. Em parte, a Danse du Sabre, I emerge da abertura para a diferença Ashanti e para o mundo que caracteriza o cinematógrafo como aparelho. Ao mesmo tempo, a vista 441 emerge também do fechamento, da captura, do dispositivo que procura submeter o aparelho cinematográfico ao desejo de extrair da diferença (e do mundo) uma mais-valia espetacular, por meio de sua contenção e exposição. A abertura do aparelho torna possivel que as imagens registrem indícios do que escapa ou resiste ao fechamento do dispositivo, que opera por meio de uma violência que apaga seus próprios rastros.

No cerne da Danse du Sabre, I, está um dos signos mais ambivalentes da extração da mais-valia espetacular da alteridade Ashanti e, ao mesmo tempo, da interrupção desse círculo econômico, decorrente da insinuação de uma desobediência. É no centro da atração espetacular que se pode reconhecer uma potência de descentramento, a figura espectral de um levante recorrente e recorrentemente fracassado contra a captura: um dos homens se vira mais de uma vez em direção ao aparelho. Na frequência recorrente dessas viradas, a violência colonial é confrontada por uma contra-violência insinuada, que a noção de cinema de atrações corre o risco de conter na ordem do espetáculo. As viradas confrontam o olhar que orienta o aparelho, mas essa confrontação permanece parcial, insuficiente, precária, até que finalmente fracassa.

No presente da filmagem, conforme destaca Groo (2019, p. 63, tradução nossa), a confrontação "entre a tribo Ashanti, de um lado, e o poder tecnológico e colonial, de outro, falha em deslocar o equilíbrio de formas que realmente importam", porque "[o]s homens e as mulheres Ashanti permanecem confinados a uma estranha pseudo-aldeia, com seus únicos caminhos de fuga conduzindo para fora de um quadro de filme" ${ }^{\prime 41}$. Mas, ainda que esse precário gesto de confrontação não tenha perturbado o dispositivo de confinamento do zoológico humano, ele abala a economia interna da imagem ao explicitar a operação de apagamento que a constitui e inscrever um rastro desse apagamento na memória do mundo: uma desobediência se insinua em meio à promessa enciclopédica e ao espetáculo do exótico.

A leitura de Groo (2019, p. 63, tradução nossa) parte do olhar branco materializado na imagem, para argumentar que "os filmes Ashanti registram e re(a)presentam [re-present] as instabilidades inerentes à apropriação visual e física". Para ela, "[e]sses filmes captam os rastros de conflito e resistência [...] que emergem entre a ideologia e os sujeitos e espaços reais" e "não superam as restrições ideológicas, mas as tornam visiveis"ไ2. Na nossa visão, ler a vista 441 anarquivicamente é suplementar o olhar materializado na imagem com o olhar opositor que se situa em seu cerne e que irradia sua desobediência informe sobre sua superfície.

41 No original: "between the Ashanti tribe, on the one hand, and technological and colonial power, on the other, fails to shift the balance in ways that really matter. The Ashanti men and women remain confined to a strange pseudovillage, with their only paths of escape leading out of a film frame."

42 No original: "the Ashanti films record and re-present the inherent instabilities of visual and physical appropriation. These films capture the traces of conflict and resistance [...] that emerge between ideology and real subjects and spaces. That is, these films do not overcome ideological strictures but make them visible." 
É preciso escutar cuidadosamente a frequência inaudivel da desobediência informe desse gesto recorrente, por meio de uma arqueologia do sensivel, além dos discursos, saberes e enunciados, se quisermos compreender os sentidos do cinema como memória do mundo. Este homem se vira e interrompe a cada vez o jogo da extração da mais-valia espetacular, que incide sobre seu próprio corpo, para em seguida retornar à dança, à imitação, enfim, ao jogo em que está confinado; este homem gesticula e interpela o vazio do extracampo frontal, que ocupamos a cada vez que assistimos à Danse du Sabre, I; este homem desobedece à forma do confinamento com um gesto informe de fuga. É impossível escutar sua voz dentro do jogo do dispositivo, e resta apenas a vibração inaudivel de seu ruído negro, sua perturbação da transparência pretendida pelo dispositivo cosmotécnico, a fresta cosmopoética de sua desobediência informe, por meio da qual se insinuam outros modos de compreender a história do cinema e outras invenções de mundos possiveis. 


\section{Referências}

AGAMBEN, Giorgio. $\mathbf{O}$ que é o contemporâneo? e outros ensaios. Tradução: Vinicius Nicastro Honesko. Chapecó, SC: Argos, 2009.

AUBERT, Michelle; SEGUIN, Jean-Claude (Dir.). La production cinématographique des Frères Lumière. Paris: Centre National de la Cinématographie, 1996.

BANCEL, Nicolas; BLANCHARD, Pascal; BOËTSCH, Gilles; et al. Introduction - Zoos humains: entre mythe et réalité. In: BANCEL, Nicolas (Org.). Zoos humains: au temps des exhibitions humaines. Éd. de poche. Paris: La Découverte, 2004, p. 5-18.

BARTHES, Roland. Les planches de l'« Encyclopédie ». In: . Nouveaux essais critiques. Paris: Seuil, 1972. Disponivel em: <http://www.ae-lib.org.ua/texts/barthes_nouveaux_essais_critiques_fr.htm\#2>. Acesso em: 02 jun. 2020.

BATAILLE, Georges. Documents. Tradução: João Camillo Penna e Marcelo Jacques de Moraes. Desterro [Florianópolis]: Cultura e Barbárie, 2018.

COSTA, Flávia Cesarino. 0 primeiro cinema. Rio de Janeiro: Azougue Editorial, 2005.

DANSE DU SABRE, I. Direção/Realização: Maison Lumière. Produtora: Maison Lumière. França, 1897. Disponivel no canal de YouTube Films by the Year: https://www.youtube.com/watch?v=uNVtkCQwL9E; acesso em: 25 jun. 2021. Vídeo digital. 39 seg., sem som, preto e branco. Digitalização de baixa qualidade de filme 35mm. Razão de aspecto: 1,33:1.

DÉOTTE, Jean-Louis. L'époque des appareils. Paris: Lignes \& Manifestes, 2004.

DERRIDA, Jacques. Mal de arquivo. Tradução: Claudia de Moraes Rego. Rio de Janeiro: Relume Dumará, 2001.

DIDI-HUBERMAN, Georges. A semelhança informe: ou o gaio saber visual segundo Georges Bataille. Tradução: Caio Meira e Fernando Scheib. Rio de Janeiro: Contraponto, 2015.

FERREIRA, Jairo. Cinema de invenção. Rio de Janeiro: Azougue Editorial, 2016.

GAUDREAULT, André. Cinématographie et attraction. Paris: CNRS, 2008.

GROO, Katherine. Bad film histories: ethnography and the early archive. Minneapolis, London: University of Minnesota Press, 2019.

GUNNING, Tom. El cine temprano como cine global: La ambición enciclopédica. Tradução: Riccardo Boglione e Georgina Torello. Vivomatografias, v. 0, n. 1, p. 171-183, 2015. Disponivel em: <http://www. vivomatografias.com/index.php/vmfs/article/view/27>. Acesso em: 02 jun. 2020. 
HEIDEGGER, Martin. A questão da técnica. Scientiae Studia, São Paulo, v. 5, n. 3, p. 375-398, set. 2007. Disponivel em: <https://doi.org/10.1590/S1678-31662007000300006>. Acesso em: 13 set.2020.

HUI, Yuk. The question concerning technology in China: an essay in cosmotechnics. Fal-mouth, UK: Urbanomic, 2016.

Recursivity and Contingency. London, New York: Rowman \& Littlefield Interna-tional, 2019.

LES FILMS LUMIÈRE. Direção/Realização: Maison Lumière. Produtora: Maison Lumière. Distribuidora: Gedeon. Japão, 2005. DVD, disco 1 de caixa de 4 discos (respectivamente: 95 min.; 98 min.; 95 min.; 103 min.; coletâneas de vistas de duração variável com até 1 min. cada uma), estéreo (para os comentários contemporâneos de Bertrand Tavernier), preto e branco. Digitalização 480p de filme $35 \mathrm{~mm}$. Razão de aspecto: 1,33:1. Idioma: francês; legendas: japonês.

LUMIĖRE ! Le Cinématographe 1895-1905 - Les films Lumière présentés par Bertrand Tavernier et Thierry Frémaux. Direção/Realização: Maison Lumière. Produtora: Maison Lumière. Distribuidora: Instituto Lumière; France TV. França, 2015. Blu-ray, 2 discos (90 min.; coletânea de vistas de duração variável com até 1 min. cada uma), estéreo (para os comentários contemporâneos), preto e branco. Digitalização 1080p de filme 35mm. Razão de aspecto: 1,33:1. Idioma: francês; legendas: francês.

MICHAUD, Philippe-Alain. Filme: por uma teoria expandida do cinema. Tradução: Vera Ribeiro. Rio de Janeiro: Contraponto, 2014.

RIBEIRO, Marcelo R. S. Do inimaginável. Goiânia: Editora UFG, 2019.

SANOGO, Aboubakar. Lumière Brothers and Africa. TIFF Higher Learning. Palestra, 2011. Disponivel em: <https://www.tiff.net/the-review/aboubakar-sanogo-on-the-lumiere-brothers-and-africa/>; <https://www. youtube.com/watch?v=oymi18Tn6XY>. Acesso em: 02 jun. 2020.

UNESCO. Memory of the World Register. Memory of the World. 2017. Disponivel em: <https://en.unesco.org/ programme/mow/register>. Acesso em: 24 jun. 2021.

UZOIGWE, Godfrey N. Partilha europeia e conquista da África: apanhado geral. In: BOAHEN, Albert Adu (Ed.). História geral da África, VII: África sob dominação colonial, 1880-1955. 2. ed. rev. Brasília: UNESCO, 2010. p. 21-50. 


\section{Informações sobre 0 artigo}

\section{Resultado de projeto de pesquisa, de dissertação, tese}

Este artigo é um dos resultados do projeto de pesquisa "O paradigma anarquívico e o arquivo colonial-moderno no cinema e no audiovisual", desenvolvido e coordenado pelo autor na Faculdade de Comunicação da Universidade Federal da Bahia, a partir de 2020, e de estudos anteriores realizados em estágio de pós-doutorado no Programa de Pós-Graduação em Letras e Linguística da Universidade Federal de Goiás (2016-2017), com o projeto “Literatura mundial e cinema mundial: genealogia conceitual e atlas de cosmopoéticas".

\section{Fontes de financiamento}

CNPq e CAPES.

\section{Considerações éticas}

Não se aplica.

\section{Declaração de conflito de interesses}

Não se aplica.

\section{Apresentação anterior}

Algumas ideias aqui discutidas foram apresentadas e debatidas no Grupo de Trabalho "Estudos de cinema, fotografia e audiovisual", no XXVI Encontro Anual da Compós (2017), e publicadas nos anais do evento, com o título "Para um atlas de cosmopoéticas: literatura mundial, cinema mundial e o catálogo Lumière como atlas".

\section{Agradecimentos/Contribuições adicionais}

Agradeço a cada participante das ocasiões mencionadas, pela escuta atenta, pelas críticas e sugestões. Agradeço igualmente pelas avaliações anônimas recebidas no decorrer do processo de revisão cega por pares. 